\title{
Non-Restrictive Relative Clauses in Arabic
}

\author{
Abdulrahman Alqurashi ${ }^{1}$ \\ ${ }^{1}$ Department of European Languages \& literature, King Abdelaziz University, Jeddah, Saudi Arabia \\ Correspondence: Abdulrahman Alqurashi, P.O. BOX 80200, Jeddah 21589, Saudi Arabia.
}

Received: June 6, 2018

doi:10.5430/elr.v7n2p54
Accepted: June 17, $2018 \quad$ Online Published: June 18, 2018

URL: https://doi.org/10.5430/elr.v7n2p54

\begin{abstract}
This paper discusses the syntax of non-restrictive relative clauses in Modern Standard Arabic (MSA). It provides a thorough description of their structures and attempts to offer a preliminary analysis within the transformation framework: Minimalist syntax. Two relativization strategies are available for Arabic non-restrictive relative clauses. The first strategy is similar to that of definite restrictive relatives in which the relative clause is initiated by ?allað $i$ which is a relative complementizer, whereas the second strategy is a unique one in which the relative clause is initiated by the special particle $w a$, appears to be a specifying coordinator, along with the complementizer ?allaði. The paper also argues that De-Vries's (2006) coordinate approach to appositive relatives can provide a straightforward account for some the facts of non-restrictive relative clauses in Arabic.
\end{abstract}

Keywords: restrictive, non-restrictive, coordinator, relative complementizer

\section{Introduction}

The syntax of relative clauses that has been the focus of much interest among linguists since Ross (1967). There is a considerable number of significant discussions of relative clauses in English and other languages (see e.g. Jackendoff, 1977; Chomsky, 1977; Fabb, 1990; Kayne ,1994; Borsley, 1992, 1997; Alexiadou et al., 2000; Arnold, 2004,2007; Bianchi, 1999, 2000, 2002a, 2002b; de Vries, 2002,2006; and Aoun \& Li, 2003). However, the syntax of Arabic relative clauses has received very limited attention in the literature. Although there are some previous generative work on relative clauses in Arabic (see e.g. Ouhalla, 2004; Aoun, Benmamoun and Choueri 2010; Alqurashi \& Borsley, 2012; Alqurashi, 2016), the focus was on restrictive relative clauses (henceforth, RRCs) and headless/free relatives only. To the best of my knowledge, neither a description nor a formal analysis of non-restrictive relative clauses (henceforth, NRRCs) in MSA has been provided yet. Moreover, it seems that this type of relative clauses has not been noticed in traditional Arab grammatical literature. Therefore, this paper aims to describe NRRCs in MSA and to provide a preliminary analysis within the transformational framework: Minimalist syntax.

Semantically, the difference between a RRC and a NRRC lies in the fact that the former provides essential information to identify the referent (i.e. the modified noun) whereas the latter provides additional information about the referent, which can be identified independently. Examples of definite RRCs and NRRCs in MSA are given in (1) and (2) below, respectively.

\section{(1) Restrictive Relatives:}

a. maata r-rajul-u llaðii zaara _ l-mdrast-a. died.3.M.SG DEF-man-NOM that.M.SG visited.3.M.SG DEF-school-ACC

'The man who/that visited the school yesterday died.'

b. jaa?a r-rajul-u llaðii tuhib-hu 1-fatat-u.

came.3.M.SG DEF-man-NOM that.M.SG love.3.F.SG-3.M.SG DEF-girl-NOM

'The man who/that the girl loves came.'

(2) Non-restrictive Relatives:

$\begin{array}{lllrrr}\text { a. fii Saam-i 2016, } & \text { maata } & \text { Muhammad-u } & \text { Ali-in } & \text { llaðii } & \text { kaan } \\ \text { in year-GEN 2016, } & \text { died.3.M.SG } & \text { Muhammad-NOM } & \text { Ali-GEN } & \text { that.M.SG } & \text { was.3.M.SG } \\ \text { min Pašhari } & & \text { PabTaal-i } & \text { l-mulaakamat-i } & \text { fii } & \text { 1-Yaalam }\end{array}$


of most-famous-GEN champions-GEN DEF-boxing-GEN in DEF-world

'Muhammad Ali, who was one of the most famous boxing champions in the world, died in 2016.'

b. fii Saam-i 2016, maata Muћammad-u Ali-in llaðii yaYrifu-hu in year-GEN 2016, died.3.M.SG Muhammad-NOM Ali-GEN that.M.SG know.3.M.SG-3.M.SG muৎð`am-u 1-naas-i.

most-NOM DEF-people-GEN

'Muhammad Ali, whom most people know, died in year 2016.'

A preliminary look at Arabic NRRCS shows they have the same structure as that of definite RRCs, discussed in Alqurashi \& Borsely (2012), which are introduced by the relative complementizer ?allaði followed by a clause which might contain either a gap or a resumptive clitc. However, the examples in (2) have a proper name as the antecedent which makes them non-restrictive. It is quite accepted that relative clauses with proper nouns as their heads can only have a non-restrictive interpretation.

However, I will show in this paper that there is a further relativization strategy available for Arabic NRRCs which involves the insertion of the particle $w a$ immediately before ?allaði. This particle is crucial to mark the non-restrictive/appositive interpretation of relative clauses. I argue that $w a$ is best seen as what De Vries (2006) calls a 'specifying coordinator'. I also argue that Arabic data can be handled straightforwardly within De-Vries's (2006) coordinate approach to appositive relatives.

The remaining of this paper will be as follows. In section 2, I will consider the basic semantics and phonological properties of NRRCs. Then in section, I will discuss the syntactic properties and distribution of NRRCs. In section 4, I will investigate the nature of the relative marker Pallaði and the nature of the particle $w a$ to determine their categorical status. Then, I will consider in section 5 a preliminary analysis for Arabic NRRCs within transformational grammar. Finally, I will conclude the paper in section 6.

\section{Some Semantic and Phonological Properties}

It has been widely observed that NRRCs differs from RRCs not only in their sematic properties but also in their phonological and syntactic ones (see Fabb, 1990; Borsley, 1992, 1997; Arnold, 2004,2007; Camilleri \& Sadler, 2011) (Note 2). From a semantic prospective, RRCs restrict or narrow down the identity of their referent (i.e. the modified noun) to be a member of a specific class whereas NRRCs do not. Simply, while RRCs provide essential information for the identification of the referent, NRRCs provide additional information about the referent, which can be identified independently. Thus, NRRCs but not RRCs can be easily omitted from the sentence without affecting the interpretation. In addition, the additional information which the NRRC provides can be then expressed by a separate sentence as shown in (3) below which expresses almost the same meaning expressed by (2a) above.

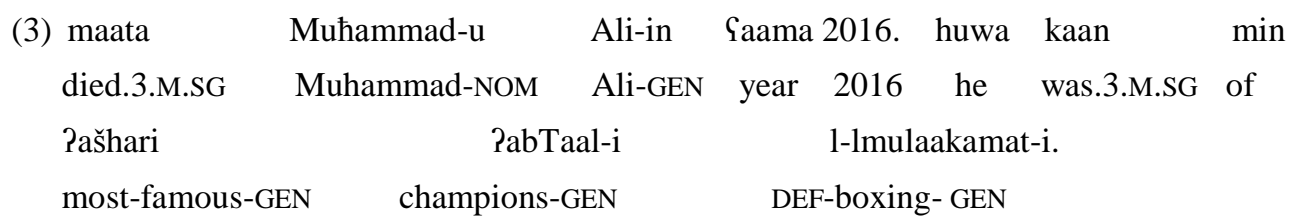

'Muhammad Ali died in year 2016. He one of the most famous boxing champions.'

From a phonological prospective, NRRCs, unlike RRCs, have distinct intonational features. Thus, in speech, NRRs are often separated from the antecedent by an intonation break (i.e. a small pause). In writing, this is represented by the use of commas in English as NRRCs are often preceded and followed by commas. This has been observed in English and some other languages like Maltese (see, Arnold, 2007; Camilleri \& Sadler, 2011). However, this phonological distinction between NRRCs and RRCs is not observed in Arabic as both types of relative clauses in (1) and (2) above are pronounced with the same intonational pattern. Consequently, neither pauses (in speech) nor commas (in written forms) are used in Arabic NRRCs to indicate some sort of phonological distinction. Due to the lack of the phonological distinction between RRCs and NRRCs which is essential to identify the latter, I was inclined to use relative clauses with a proper noun as the antecedent in the previous NRRCs examples, which is generally accepted to be antecedent of non-restrictives.

However, NRRCs can be expressed sometimes with the morpheme / $\mathrm{wa}$ / immediately preceding the relative marker. Badawi et al (2004: 503), in their modern descriptive work on Arabic, states that "Restrictive and non-restrictive 
relative clauses do not have to be formally distinguished". They briefly point out that there is an alternative way to distinguish NRRCs by introducing them with /wa/ as illustrated by the example in (4) provided by them.

\begin{tabular}{|c|c|c|c|c|}
\hline $\begin{array}{l}\text { Pillaa } \\
\text { although }\end{array}$ & $\begin{array}{l}\text { Panna fikra-hu } \\
\text { COMP thought-3.M.SG }\end{array}$ & $\begin{array}{l}\text { 1-qaaTiৎ-a } \\
\text { DEF-dicisive-ACC }\end{array}$ & $\begin{array}{l}\text { 1-Saarim-a } \\
\text { DEF-relentless-ACC }\end{array}$ & $\begin{array}{l}\text { 1-mutašaddid-a } \\
\text { DEF- severe-ACC }\end{array}$ \\
\hline & $\begin{array}{l}\text { Taraћah-hu } \\
\text { presented.3.M. }\end{array}$ & $\begin{array}{ccc} & \text { fi kitaab } \\
\text { M.SG } & \text { in book- }\end{array}$ & 3.M.SG & \\
\hline
\end{tabular}

'although his decisive, severe, relentless thought, which he presented in his book'

(Badawi et al, 2004: 503)

In fact, introducing the NRRCs in (2) above with /wa/ will make the sentences sound better as shown in (5) below. I believe that using the particle /wa/ necessitates the existence of a small pause in order to separate the relative clause from the modified noun. It should be mentioned here, however, that the morpheme / $w a /$ is an equivalent of 'and' in English, but it is not clear at this stage whether to treat it as a coordinator or as something else, as this will be discussed later (see section 5 for more discussion on the nature of /wa/).

(5) Non-restrictive Relatives with /wa/:

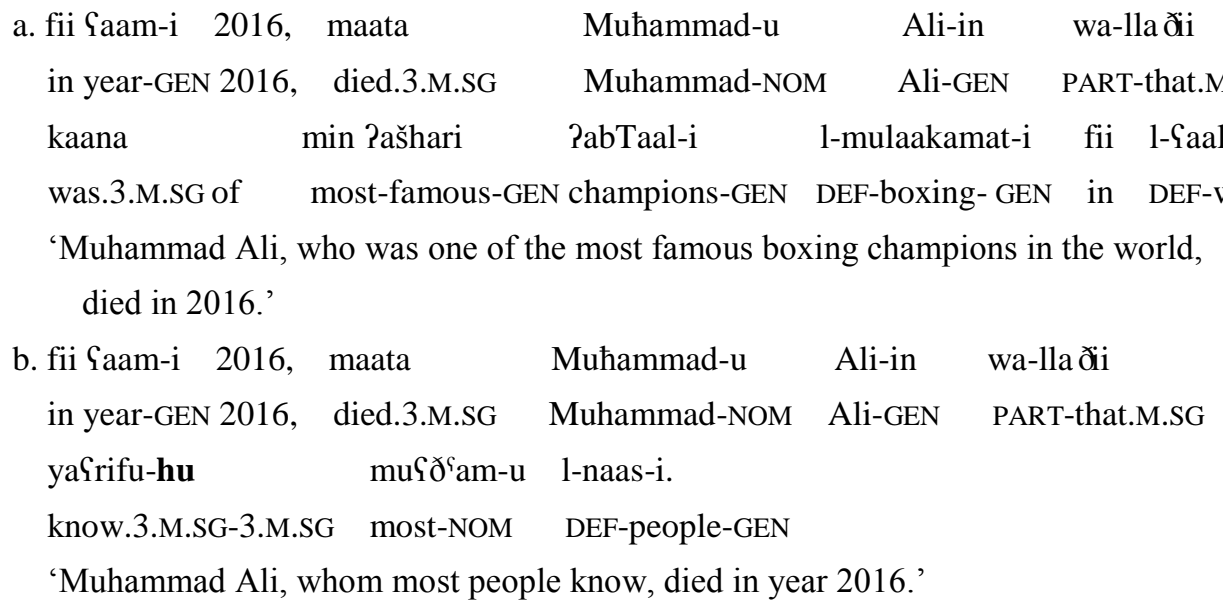

Badawi et al (2004) neither discuss this any further nor present any argument, which might be due to the general descriptive nature of their work. I claim that the use of $w a$ in the above relative clauses in (4) and (5) yields in a non-restrictive interpretation only based on the following evidence. It has been attested in Arabic literature that the morpheme /wa/ is obligatorily used sometimes along with a small pause as a break to separate a phrase or a clause from a preceding element to avoid misinterpretation. Consider the following: (Note 3)
ALLAH.
no healed.3.M.SG-2.M.SG ALLAH (God)
(6) laa Paafaa-ka
'may ALLAH (GOD) not keep you healthy.'
(7) laa wa Paafaa-ka ALLAH.
no PART healed.3.M.SG-2.M.SG ALLAH (God)

'No, may ALLAH (GOD) keep you healthy.'

These examples show clearly that the use of the particle $w a$ is of great significance to the meaning as it prevents wrong interpretation. The initial intended meaning in (6) is the same as in (7), but the lack of the particle wa yields a completely different meaning. Additionally, the use of the particle wa necessitates the existence of a small pause before pronouncing it in order to separate the negation particle la "no" from the rest of the sentence.

Having considered the semantic and phonological properties of NRRCs, let us now discuss the syntactic properties that distinguishes them from RRCs. This, however, will be dealt with in the following section.

\section{Syntactic Properties and Distribution}

Based on the discussion above, we can now say that NRRCs in Arabic use two strategies. The first is exactly similar to the relativization strategy used to generate definite RRCs which consist of a relative complementizer followed by a clause in which either a resumptive clitic or a gap exists, as shown in (1) and (2) above. The second strategy 
involves the use of the particle $w a$ which is inserted immediately before Pallað $i$ that introduces the relative clause in which there is either a resumptive clitic or a gap, as shown in (5) above. Different examples are given in (8) and (9) to represent the two types of Arabic NRRCs, respectively. Note that Pallaði is always inflected for gender and number and sometimes case as a result of agreement with the antecedent, as will be shown later in section 4. (Note 4)

(8) yaGiišu Sadiiqi fii Paariis llatii hiya madiinat-u-n kabiirah.

live.3.M.SG my friend in Paris-NOM that.F.SG it/she city.F-NOM-INDEF big.F

'My friend lives in Paris, which is a big city.'

(9) yaGiišu Sadiiqi fii Paariis wa-llatii hiya madiinat-u-n kabiirah.

live.3.M.SG my friend in Paris-NOM PART-that.F.SG it/she city.F-NOM-INDEF big.F

'My friend lives in Paris, which is a big city.'

The question arises here is why the second strategy is needed to express NRRCs in Arabic. As mention above, the intonational properties that exist in English NRRCs are not observed in Arabic. With the lack of these properties, it would be difficult to distinguish NRRCS from RRCs. Thus, the particle $w a$, whose use necessitates the existence of a small pause, is inserted pre-Pallaði to ensure that the NRRC is set off prosodically. Moreover, relative clauses modifying proper nouns are easy to distinguish because they can only have a non-restrictive interpretation. However, this is not with case with NRRCs modifying common nouns as they are difficult to be distinguished from RRCs. Therefore, this might evoke the use $w a$ as a means of distinction. To illustrated further consider the following examples.
(10) s-sayarat-u latii
DEF-cars-NOM that.F.SG
colour-3.F.PL black expensive-NOM
DEF-price
lawnu-ha ?swad galiyat-u
1- $\theta$ aman. (RRC)
'The cars which are black are expensive.'
(11) s-sayarat-u wa-llatii lawnu-ha
?swad galiyat-u
DEF-cars-NOM
PART-that.F.SG
colour-3.F.PL
black expensive-NOM
1- $\theta$ aman. (NRRC)

'The cars, which are black, are expensive.'

The sentence in (10), which contains a RRC, implies that the black cars are distinguished from other cars which are not black (i.e. only black cars are expensive but others are not). On the other hand, the sentences in (11), which contains a NRRC, implies that all the cars referred to here are black. It would be impossible to express the meaning in (11) if the particle $w a$ was not used pre-Pallatii to introduce the relative clause.

The case is somehow different in RRCs which are of two types: definite (with a definite antecedent) and non-definite (with an indefinite antecedent). As pointed out above, the first strategy used to generate NRRCs is also used to generate definite RCs in MSA. As for the indefinite relative clause, a different strategy is used in which no relative complementizer appears and hence the relative clause is just a simple clause in which there is either a resumptive clitic or a gap as demonstrated by the following examples:

\section{(12) Indefinite Restrictive Relatives:}
a. ra?aytu
rajul-u-n
zaara
1-mdrast-a
1-baariћata.
saw.1.SG man-NOM-INDEF
visited.3.M.SG
DEF-school-ACC
DEF-last night

'I saw a man who/that visited the school yesterday.'
b. ra?aytu. rajul-u-n
tuhib-hu
l-fatat-u.
saw.1.SG man-NOM-INDEF
love.3.F.SG-3.M.SG
DEF-girl-NOM

'I saw a man who/that the girl loves.'

Another fundamental syntactic difference between NRRCs and RCCs is that the former can have a non-nominal antecedent but not the latter. More specifically, the antecedent of a NRRC can be a VP, a PP, an AdjP, an AdvP. This has been attested in English (see e.g.; Borsley, 1992; Arnold, 2004,2007; De Vries, 2006; Citko, 2008), and in other languages (see e.g. Jackendoff, 1977 and Camilleri \& Sadler, 2011). This is also the case in MSA as non-nominal antecedents can appear only in NRRCs. More specifically, NRRCs can have a non-nominal antecedent only if the second strategy is used (i.e. introduced with wa-llaðii). Consider the following examples, where the antecedents are bracketed: 
(13) a. [faazat Hind-u fi l-musabaqat-i] wa-llaðii kasarani won.3.F.SG Hind-NOM in DEF-competition-GEN PART-that.M.SG pleased.3.M.SG-2.M.SG a lot 'Hind won the competition, which pleased me a lot.'

b. *[faazat Hind-u fi l-musabaqat-i] llaðii Pasarani ka0iiran. won.3.F.SG Hind-NOM in DEF-competition-GEN that.M.SG pleased.3.M.SG-2.M.SG a lot 'Hind won the competition which pleased me a lot.'

$\begin{array}{lllllllll}\text { (14) a. } & \text { [istaqaalt }] & \text { Hind-u } & \text { min } & \text { Samali-ha } & \text { wa-llaðii } & \text { lan } & \text { PafSal-hu } & \text { Pabada. } \\ & \text { resigned.3.F.SG } & \text { Hind-NOM } & \text { from } & \text { work-3.F.SG } & \text { PART-that.M.SG } & \text { NEG } & \text { do.1.SG-3.M.SG } & \text { never }\end{array}$ 'Hind resigned from her work, which I will never do.'

b. *[istaqaalt] Hind-u min Samali-ha llaðii lan PafSal-hu Pabada. resigned.3.F.SG Hind-NOM from work-3.F.SG that.M.SG NEG do.1.SG-3.M.SG never 'Hind resigned from her work, which I will never do.'

(15) a. Ali-un [haziil-un jiddan] wa-llaðii lam Patawaqs-hu Pan

Ali-NOM thin.3.M.SG-ACC very PART-that.M.SG NEG.PAST expected.1.SG-3.M.SG COMP yakuuna kaðaalik.

be.3.M.SG like-that

'Ali looked very thin, which I did not expect that he will be.'

b. *Ali-un [haziil-un jiddan] llaðii lam Patawaqৎ-hu Pan

Ali-NOM thin.3.M.SG-ACC very that.M.SG NEG.PAST expected.1.SG-3.M.SGCOMP

yakuuna kaðaalik.

be.3.M.SG like-that

'Ali looked very thin, which I did not expect that he will be.'

The above examples show clearly that NRRCs but not RRCs can have a non-nominal antecedent. The antecedent is a clause in (13), a VP in (14) and an AdjP in (15), thus it must be followed by a NRRC to be acceptable as in (13a), (14a) and (15a). It is unacceptable to have a RRC with these antecedents as (13b), (14b) and (15b) demonstrate.

Furthermore, Arnload and Borsley (2008) note that NRRCs differ from RRCs in English in that the former can have elliptical answers to questions and propositional lexemes like yes as antecedents as shown below:

(16) A: Who owns a dog?

B: Kim, which is regrettable. (Arnload and Borsley, 2008:327)

(17) A: Does Kim own a dog?

B: Yes, which is regrettable. (Arnload and Borsley, 2008:328)

We have the same situation in Arabic as the following examples illustrate:
(18) A: man kasara 1-naafiðat-a?
who broke-3.M.SG DEF-window-ACC
'Who broke the window?'
B: Zyed, wa-llaðii kaan mu?ssif-an jiddan
Zayd PART-that.M.SG was regretable-ACC very
'Zayd, which was regrettable.'
(19) A: hal kasara Zyed-un 1-naafiðat-a?
who broke-3.M.SG Zyed-NOM DEF-window-ACC
'Who broke the window?'
B: naSam, wa-llaðii kaan mu?ssif-an jiddan
yes PART-that.M.SG was regretable-ACC very
'Yes, which was regrettable.'




\section{On the Nature of Pallaði and wa}

In Arabic NRRCs, the relative marker Pallað $i$ agrees with its antecedent in number, gender and case. Hence it has different forms as the following table illustrates:

Table 1. Forms of ?allaði

\begin{tabular}{lllcl}
\hline & Singular & $\begin{array}{l}\text { Dual } \\
\text { Nominative }\end{array}$ & \multicolumn{1}{c}{$\begin{array}{c}\text { Dual } \\
\text { Accusative/ Genitive }\end{array}$} & Plural \\
\hline Masculine & Pallað $i$ & Pallaðaani & Pallaðayni & Pallaðiina \\
Feminine & Pallati & Pallataani & Pallatayni & Pallaati/Pallawaati \\
\hline
\end{tabular}

In addition, the resumptive clitic or the gap within the relative clause agree also with Pallaði since they have to agree with the antecedent. This is demonstrated by the following examples:
jaa?a
Aћmad-u llaðii zaara
_ 1-mdrast-a
1-baariћah.
came.3.M.SG Ahmad-NOM that.M.SG visited.3.M.SG
DEF-school-ACC DEF-last night

'Ahmad, who visited the school last night, came.'

$\begin{array}{llllll}\text { yaGiišu } & \text { Sadiiqi } & \text { fii Paariis } & \text { wa-llatii } & \text { Puhib-haa } & \text { ka9iirun. } \\ \text { live.3.M.SG my friend } & \text { in Paris-NOM } & \text { PART-that.F.SG } & \text { love.1.SG-3.F.SG a lot } \\ \text { 'My friend lives in Paris, which I love a lot.' } & & \end{array}$

In (20a) and (21), the antecedent is masculine singular and thus the masculine singular form llaðii is used, whereas the antecedent in (21) is feminine singular and thus the feminine singular form llati is used. In addition, the gap in (20), which appears in subject position, and the clitic haa in (21) show agreement with both their antecedents and the relative complementizer. The agreement features of the gap (number and gender) can be identified by the associate verb zaara which is inflected as third-person masculine singular.

Furthermore, the relative complementizer also agrees with its antecedent in case, which appears only in the dual form. However, it should be noted here that when the antecedent the position being relativized bear different cases, the complemntizer Pallaði carries the case of former, not that of the latter. Thus, in (22) below, llaðaani does not bear an accusative case like that of the position being relativized, but rather a nominative case like that of its antecedent. In (23) below, the antecedent is genitive whereas the position being relativized (-humaa) is accusative and hence Pallaðayni bears genitive case like its antecedent.
(22) PxtraYaa
?al-?axawaani
Raayits
(wa)-llaðaani
invented.3.M.DUAL
DEF-brother.DUAL.NOM Wrights
PART-that.M.DUAL.NOM
yGrifu-humaa
muৎð`am-u 1-naas-i
Pawal
Ta?irah.
know.3.M.SG-3.DUAL most-NOM
DEF-people-GEN
first
plane

'The two brothers Wright, whom most people know, invented the first plane.'
(23) qar?atu Gan
1-Paxawayni
Raayits (wa)-llaðayni
read.1.SG about
DEF-brother.DUAL.GEN
Wrights
PART-that.M.DUAL.GEN
yGrifu-humaa
muৎðৎam-u 1-naas-i.
know.3.M.SG-3.DUAL most-NOM DEF-people-GEN

'The two brothers Wright, whom most people know, invented the first plane.'

This is can be used as evidence that the relative marker Pallaði cannot be seen as a relative pronoun, but rather as a complementizer, as argued by Alqurashi \& Borsely (2012) and Alqurashi (2016). If Pallaði is a relative pronoun, we would expect it to bear the case of the relativized position as relative pronouns usually do. Consider the examples in (24) from English where the relative pronoun carries the case of the associated gap and not that of the antecedent.

(24) a. The dean of the college, who met the new students yesterday, is giving a talk.

b. The dean of the college, whom the new students met yesterday, is giving a talk.

A further evidence that Pallað $i$ is a complementizer comes from the fact that it is impossible for Pallað $i$ to be in a larger clause-initial phrase like a PP or DP (see also Alqurashi \& Borsely, 2012 and Alqurashi, 2016). One would 
expect that to be possible if Pallaði is a relative pronoun. Let us now examine whether this is applicable to ?allað $i$ in NRRCs. Consider the following:

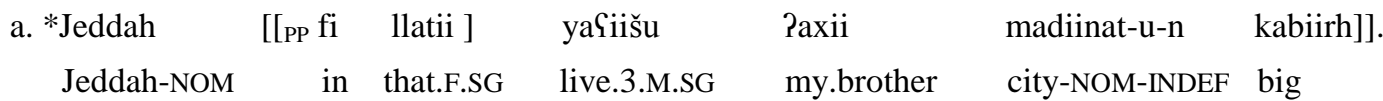

$$
\begin{aligned}
& \text { 'Jeddah, in which my brother lives, is a big city.' } \\
& \text { b. *Ibrahiim-u [ [Dp kitaab llaði] qar?atu ] } \\
& \text { Ibrahiim-NOM book that.M.SG read. PAST.2.M.SG }
\end{aligned}
$$

The above ungrammatical examples show clearly that Pallað $i$ in NRRCs does not allow pied piping. Thus, instead of (25), we have the examples in (26) in which the preposition and the noun remain in-situ with resumptive clitics.

It is not surprising, then, to see ?allaði introducing different types of relative clauses since it is just a relative complementizer. (Note 6)

It is also crucial to the analysis to determine the categorical status of $w a$; whether it must be seen as a standard conjunctive element or as something else. In MSA, the morpheme /wa/ has different uses, but it is mainly used as a conjunctive element. The fact that $w a$ is used sometimes pre-?allað $i$ to introduce non-restrictive relative clauses has been overlooked by old traditional Arab grammarians. However, this issue is under debate among some current Arab scholars. Some assume that $w a$ is a special relative element used sometimes pre-Pallað $i$ to introduce relative clauses while others reject this assumption and consider it even radical; this is on the basis that its presence causes ambiguity. Consider the following example.
(27) jaa?a
Ahmad-u wa-llaðii
zaara
1-mdrast-a
1-baariћah.
came.3.M.SG Ahmad-NOM
PART-that.M.SG visited.3.M.SG
DEF-school-ACC DEF-last night.

'Ahmad, who visited the school yesterday, came.'

'Ahmad and the one that visited the school yesterday came.'

The presence of $w a$ creates semantic ambiguity in (27) above as illustrated in the translation lines. The first meaning results from treating $w a$ as a special particle added to the relative complementizer Pallað $i$ to give the relative clause a non-restrictive interpretation. The second meaning results from treating $w a$ as a coordinator combining a free/headless relative clause with another clause. Free/headless relative clauses in MSA can be introduced by the relative complementizer Pallað $i$ as in (28).
jaa?a llaðii zaara
came.3.M.SG that.M.SG visited.3.M.SG
_ 1-mdrast-a
1-baariћah.

'Who visited the school yesterday came.'

However, the ambiguity in (29) presumably disappears if the relative clause is introduced by man or maa instead of Pallaði, which are special free relative complementizers (see, Alqurashi (2016). Consider the following example which is interpreted merely as having complex subject consisting of an NP conjoined with a free relative clause:

$$
\begin{array}{cllll}
\text { jaaPa } & \text { Ahmad-u } & \text { wa-man } & \text { zaara } & \text { 1-mdrast-a } \\
\text { came.3.M.SG } & \text { DEF-man-NOM } & \text { COORD-that.M.SG } & \text { visited.3.M.SG } & \text { DEF-school-ACC }
\end{array}
$$

'Ahmad and the one that visited the school came.'

Moreover, the ambiguity in (27) above can be avoided if we change the word order as follows:

$$
\text { Aћmad-u wa-llaðii zaara }
$$

1-mdrast-a

l-baariћat-a

jaa?a 
Ahmad-NOM PART-that.M.SG visited.3.M.SG DEF-school-ACC DEF-last night-ACC came.3.M.SG

'The man, who visited the school, came.'

$\begin{array}{lllll}\text { Ahmad-u } & \text { wa-llaðii } & \text { zaara } & \text { l-mdrast-a } & \text { jaa?aa. } \\ \text { Ahmad-NOM } & \text { and-that.M.SG } & \text { visited.3.M.SG } & \text { DEF-school-ACC } & \text { came.3.M.DUAL }\end{array}$

'The man and (the one) who visited the school came.'

The sentence in (30) is interpreted merely as one which contains a non-restrictive relative clause whereas the sentence in (31) is interpreted merely as having complex subject consisting of an NP conjoined with a free relative clause. This is due to the well-known subject-verb agreement mismatch in MSA. Subject-verb agreement in MSA is sensitive to word order. In SV word order, they agree in number, person and gender whereas in VS word order, they agree in person and gender only. Moreover, verbs agree only with the first conjunct of conjoined subjects in verb-initial clauses while in subject-initial clauses, they agree with both conjuncts. In (30) above, the verb jaa?

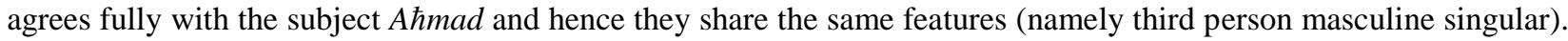
In (31), the verb jaa?aa is assigned different number feature (namely dual) because it agrees with the conjoined subject which refers to two different people. Thus, wa in (31) but not in (30) must be seen only as a standard conjunctive element.

Furthermore, the use of $w a$ in sentences like (4) and (5) above does not create any semantic ambiguity due to the presence of the resumptive clitic and, most importantly, the anaphoric clitic. They are interpreted only as ones containing a relative clause that has a non-restrictive interpretation only. Now, consider the examples in (32) and (33) in which the antecedent has to match the clitics, and hence it has to be singular in (32) and plural in (33).
(32)

$\begin{array}{lr}\text { šaraha } & \text { l-muSal } \\ \text { explained.3.M.SG } & \text { DEF-teach } \\ \text { drsa-hu } & \text { bi?itqaan. }\end{array}$
lesson-3.M.SG perfectly
'The teacher, whom the state honoured, explained his lesson perfectly.'

\begin{tabular}{|c|c|c|c|c|}
\hline šaraha & 1-muSalim-u & wa-llaðii & karamt-hu & l-dwlat-u \\
\hline explained.3.M.SG & DEF-teacher-NOM & and-that.M.SG & honoured.3.M.SG-3.M.SG & DEF-state-NOM \\
\hline drsa-humaa & biritqaan. & & & \\
\hline lesson-3.M.DUAL & perfectly & & & \\
\hline
\end{tabular}

Only (33) suggests that wa must be treated as a conjunctive coordinator. The question that arises here is whether wa in examples like e.g. (27), (30) and (5) above can be seen as a different type of coordinators. A possible solution to this dilemma is to assume, following De Vries (2006), that $w a$ is a coordinator in all examples above but with different functions. De Vries (2006:238) argues that there are three main types of coordination, namely 'conjunction, disjunction and specification' and provides the following examples to illustrated this:
(34) a. Joop and Jaap
(conjunction)
b. Joop or Jaap
(disjunction)
c. the White House, or the house with the Oval Office
(specification)

Equivalent examples are found in Arabic as shown below:
(35) a. Ali-un wa Hind-un
'Ali and Hind'
Ali-NOM and Hind-NOM
b. Ali-un Paw/Pam Hind-un
Ali-NOM or Hind-NOM
'Ali or Hind'
c. Paariis ?aw 1-madiinat-u ðaat-u 1-PaDwaa? (specification)
(conjunction)
(disjunction) 
Paris-NOM or DEF-city-NOM with-NOM DEF-lights

'Paris, or the city of lights' lit. 'the city with the lights'

A final note that should be mentioned here is that wa can appear without a coordinate structure as the example is (7) above shows. It can also be used as a subordinator to introduced explanatory and circumstantial clauses as (36) and (37), provided by Badawi et al (2004: 549,550).

$\begin{array}{lcccccc}\text { wa-zuyyina } & \text { l-naৎ̌̌-u } & \text { bi-zuhuur-i } & \text { Sala } & \text { šakli } & \text { raqm-i } & 7 \\ \text { AND-decorated.PASS } & \text { DEF-bier-NOM } & \text { with-flowers-GEN } & \text { on } & \text { shape } & \text { number-GEN } & 7 \\ \text { wa-huwa } & \text { raqm-u } & \text { l-qamiis-i } & \text { llaðii } & \text { kaana yartadii-hi } & \text { Matthews ... }\end{array}$

'and the bier was decorated in the shape of a number 7, this being the number of the shirt which Matthews used to wear...'

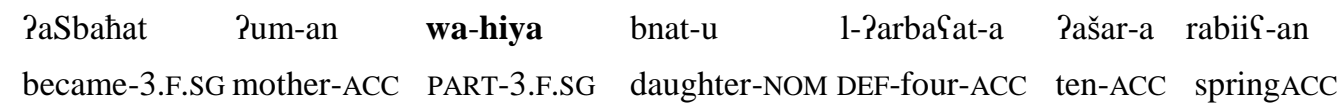

'She became a mother when she was fourteen.', lit. 'and she the daughter of fourteen springs?'

\section{Analysis}

De Vries (2006) argues that English appositive relatives assimilate coordination structures. He hypothetically assumes a null specifying coordinator which coordinates the appositive relative clause to the antecedent. Thus, for the NRRCs in (35), he assumes the structure in (36) below. (Note 2)

(38) John who I know well

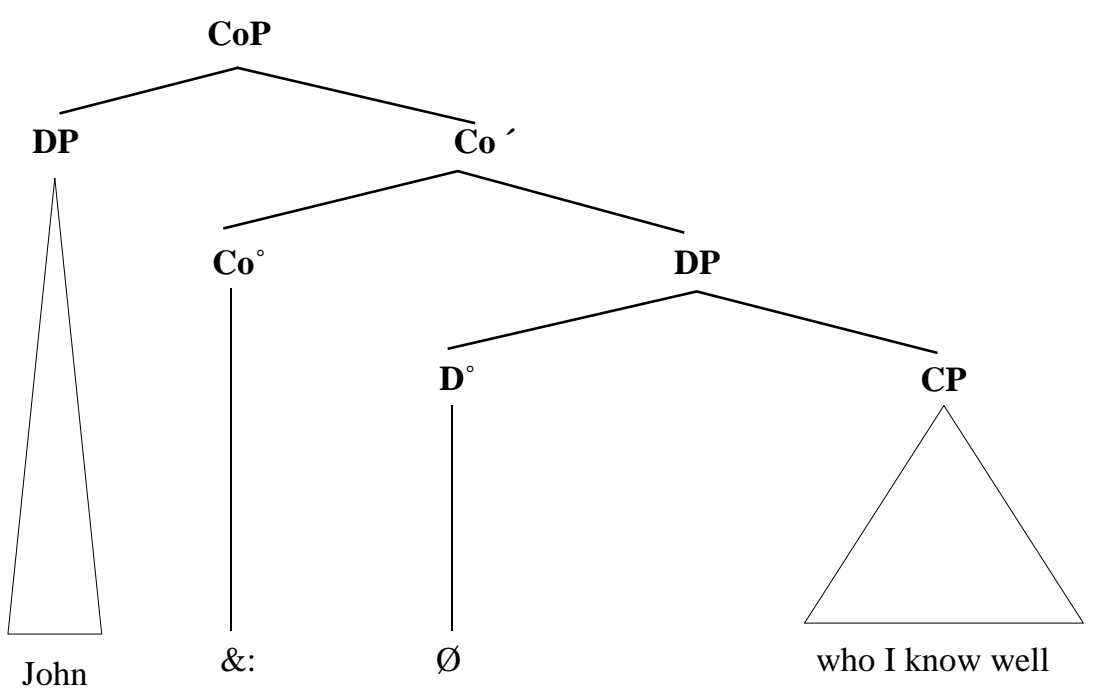

Furthermore, De Vries (2006) assumes that the appositive clause is not a CP but rather a DP, more specifically, it is a kind of free relative headed by a null $\mathrm{D}$ in apposition to the antecedent. He calls it a false free relative as he distinguishes between true and false free relatives based on examples from Dutch (see section 4.2 in the work cited above) which show that only false relatives can have a pronominal antecedent, but not true free relatives whose antecedent is implied in the relative pronoun. He also assumes raising within the relative clause (raising of an abstract NP within the second conjunct). In fact, the full structure he provides, schematized in (40) below, looks more complex that the one in (39) above.

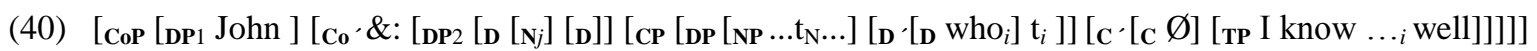

However, De Vries's (2006) analysis can be adopted here with some modifications to account for Arabic NRRCs that are introduced by $w a$, which should be treated as an overt specifying coordinator. Unlike De Vries (2006), I will not assume raising within Arabic NRRCs but I will rather assume movement of an empty relative operator. In addition, I will use De Vries's classification of free relatives but in a different way. As noted in (28) above, Arabic free relatives look like RRCs in that they are introduced by the complementizer ?allað $i$ but with a null antecedent. 
Both Arabic restrictive relatives and free relatives are analysed as having an empty operator-movement. However, if we consider both relative clauses in (30) and (31) as free relative clauses in apposition to the antecedent, we should then treat them differently as they have two different interpretations. Thus, the relative clause inside the second conjunct in (30) above should be called a false free relative since it refers to the same antecedent in first conjunct. On the other hand, the relative clause in (31) has a null antecedent that is different from (does not refer to) the element in first conjunct, thus it should be called a true free relative.

It is the coordinator which determines the type of relative clause. Therefore, if $w a$ is a specifying coordinator as in (30), then the following clause is a false free relative; and if it is a conjunctive coordinator as in e.g. (31), then the following clause is a true free relative. Thus assume that the NRRC is a false free relative clause.

As for NRRCs with resumptive clitics, there exists an evidence pointed out by Alqurashi \& Borsely (2012) that resumptive clitics behave like gaps with respect to Coordinate Structures and Parasitic Gaps. In conformity with Ross's (1967) Coordinate Structure Constraint, movement cannot affect the first conjunct of the coordinate structure without affecting the other(s). This suggests they must be treated alike. Consider the coordinate structure in (41) whose first conjunct contains a gap whereas the second contains a resumptive clitic; and consider also the example in (42) in which a parasitic gap is licenced by a resumptive clitic:
(41)
l-fatatu llati Puhibu
wa ?ahras
Salay-ha
the-girl-NOM that- F.SG love.1.M.SG and care.1.M.SG about-3.F.SG
'the girl that I love and care about'
1-kitaab-u llaðii
š-štaraa-hu
Ali duuna ?an yaqra?
DEF-book- NOM COMP.M.SG bought.3.M.SG- 3.M.SG Ali without that read. 3.M.SG
'the book that Ali bought without reading'

It can be said, then, that both NRRCs containing gaps and those containing resumptive clitics can be accounted for by an operator movement. Thus, the NRRC in (5b) above, repeated in (43) for convenience, is assumed to have the structure in (44) below.
Muhammad-u
Ali-in
wa-llaðii
yaGrifu-hu
muৎðৎam-u 1-naas
Muhammad-NOM Ali-GEN COORD-that.M.SG
know.3.M.SG-3.M.SG most-NOM DEF-people

'Muhammad Ali, whom most people know,'

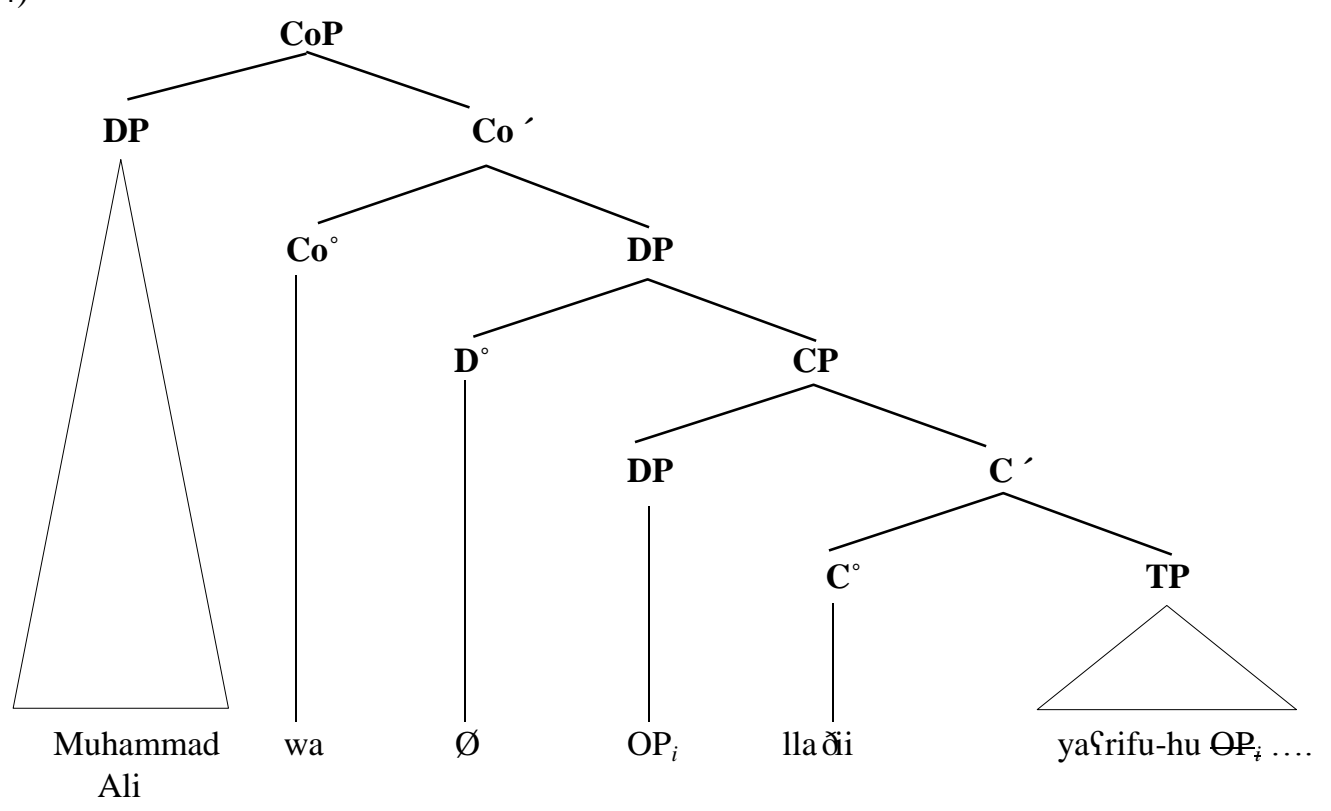

As for NRRCs which are not introduced by an overt coordinator, like in (2) above, they are assumed to have a null specifying coordinator. Thus, the sentence in $(2 \mathrm{~b})$ above will have the structure in (45) below. 

Muhammad-u Ali-in llaðii
yaSrifu-hu
muৎðৎam-u 1-naas
Muhammad-NOM Ali-GEN
that.M.SG
know.3.M.SG-3.M.SG
most-NOM
DEF-people

'Muhammad Ali, whom most people know,'

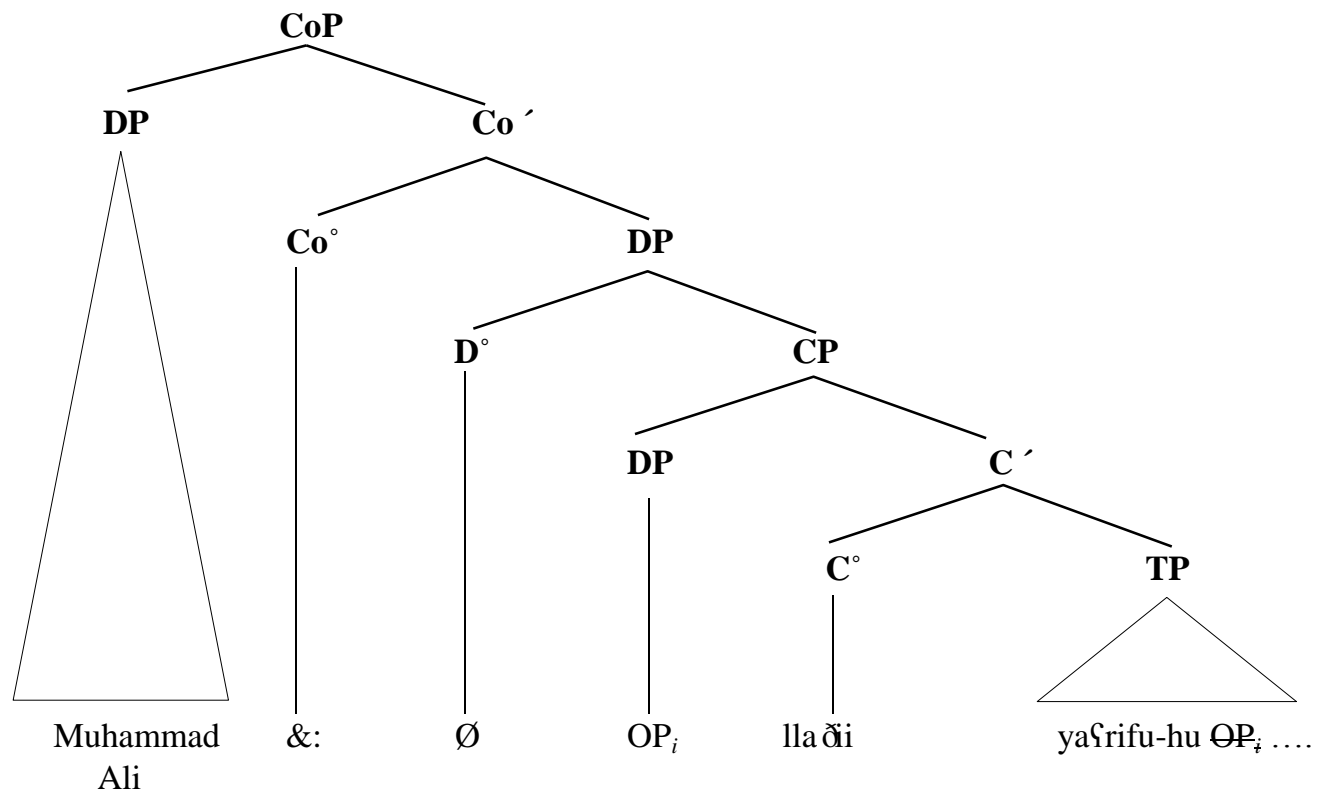

The final point that should be noted here is to account for NRRCs with non-nominal antecedents like a clause, a VP or an AdjP as shown in (13-15). These types of NRRCs can be accommodated within De-Vries's (2006) coordinate approach if assume that the head of the free relative clause inside the second conjunct is the same as the antecedent in the first conjunct. Thus, we can have a structure similar to the one in (44) but with an XP instead of the DP in the two conjuncts, where $\mathrm{X}$ can stand for any syntactic category.

\section{Conclusion}

This paper has offered a description of NRRCs in MSA and attempted to provide a preliminary analysis of their structures within the transformational framework: Minimalist syntax. It has shown clearly that Arabic non-restrictive relative clauses can be generated via two relativization strategies: one is similar to that of definite restrictive relatives and the other involves the use the specifying coordinator $w a$ to mark the non-restrictive interpretation. The paper has also argued that that the particle $w a$ is best treated as a specifying coordinator and that De-Vries's (2006) coordinate approach to appositive relatives can be adopted to provide a straightforward account for the structure of the second strategy. However, raising analysis is not assumed but rather operator movement is assumed within the relative clause. Finally, the facts related to NRRCS might provide some support to De-Vries's (2006) assumption that NRRCs assimilate coordinate structures.

\section{Acknowledgements}

This Project was funded by the Deanship of Scientific Research (DSR), at King Abdulaziz University, Jeddah, under grant no.G-87-125-1439. The author, therefore, acknowledge with thanks DSR for technical and financial support.

I am also grateful to Bob Borsley, Maather Alrawi, Adel Alzahrani and Michael Hahn for their constructive and helpful comments on an early version of this paper. Any errors or inaccuracies are my responsibility alone.

\section{References}

Alexiadou, A., Law, P., Meinunger, A., \& Wilder, C. (Eds.). (2000). The syntax of relative clauses. Amsterdam and Philadelphia: John Benjamins. https://doi.org/10.1075/la.32

Alqurashi, A. (2016). An HPSG Approach to Free Relatives in Arabic. International Journal of English Language and Linguistics Research, 4(1), 70-87. 
Alqurashi, A., \& Borsley, R. (2012). Arabic Relative Clauses in HPSG. In S. Müller (Ed.), Proceedings of the 19th International Conference on Head-Driven Phrase Structure Grammar (pp. 26-44). Stanford, CA: CSLI Publications.

Alotaibi, M., \& Borsley, R. D. (2013). Gaps and Resumptive Pronouns in Modern Standard Arabic. In S. Müller (Ed.), Proceedings of the 20th International Conference on Head-Driven Phrase Structure Grammar (pp. 6-26). Stanford, CA: CSLI Publications.

Aoun, J., Choueiri, L., \& Benmamoun, E. (2010). The syntax of Arabic. Cambridge: Cambridge University Press.

Aoun, J., \& Li, Y. A. (2003). Essays on the representational and derivational nature of grammar: the diversity of wh-constructions. Cambridge, Mass.: MIT press.

Arnold, D. (2004). Non-restrictive relative clauses in construction based HPSG. In S. Müller (Ed.), Proceedings of the 11th International Conference on Head-Driven Phrase Structure Grammar (pp. 27-47). Stanford, CA: CSLI Publications.

Arnold, D.J. (2007). Non-Restrictive relatives are not orphans. Journal of Linguistics, 43(2), 272-309. https://doi.org/10.1017/S0022226707004586

Arnold, Doug, \& Borsley, Robert D. (2008). Non-restrictive Relative Clauses, Ellipsis and Anaphora. In Stefan Mu 1ler (Ed.): Proceedings of the 15th International Conference on Head-Driven Phrase Structure Grammar, (pp. 325-345). Stanford, CA: CSLI Publications.

Badawi, E., Carter, M., \& Gully, A. (2004). Modern written Arabic: a comprehensive grammar. London: Routledge.

Bianchi, V. (1999). Consequences of antisymmetry: Headed relative clauses. New York: Mouton de Gruyter. https://doi.org/10.1515/9783110803372

Bianchi, V. (2000). The raising analysis of relative clauses: A reply to Borsley. Linguistic Inquiry, 31(1), 123-140. https://doi.org/10.1162/002438900554316

Borsley, R.D. (1992). More on the difference between English restrictive relative clauses. Journal of Linguistics, 28, 139-148. https://doi.org/10.1017/S0022226700015024

Borsley, R. D. (1997). Relative clauses and the theory of phrase structure. Linguistic Inquiry, 28(4), 629-647.

Camilleri, M., \& Sadler, L. (2011). An LFG Approach to Non-Restrictive Relative Clauses in Maltese. Essex Research Report in Linguistics, 60(6), 1-29.

Chomsky, N. (1977). On wh-movement. In P. Culicover, T. Wasow \& A. Akmajian (Eds.), Formal Syntax (pp. 71-132). New York: Academic Press.

Citko, B. (2008). An argument against assimilating appositive relatives to coordinate structures. Linguistic Inquiry, 39(4), 633-655. https://doi.org/10.1162/ling.2008.39.4.633

De Vries, M. (2002). The syntax of relativization. Utrecht: Lot.

De Vries, M. (2006). The syntax of appositive relativization: On specifying coordination, false free relatives, and promotion. Linguistic Inquiry, 37(2), 229-270. https://doi.org/10.1162/ling.2006.37.2.229

Fabb, N. (1990). The difference between English restrictive and non-restrictive relative clauses. Journal of Linguistics, 26, 57-77.

Kayne, R. (1994). The antisymmetry of syntax. Cambridge, Mass: The MIT Press.

Ouhalla, J. (2004). Semitic relatives. Linguistic Inquiry, 35(2), 288-300. https://doi.org/10.1162/002438904323019084

Ross, J. (1967). Constraints on Variables in Syntax. Unpublished doctoral dissertation, MIT, Cambridge, Mass.

Watson, J. C. E. (2007). The phonology and morphology of Arabic: Oxford University Press, USA. 


\section{Notes}

Note 1. Morphemes in Arabic must start with a consonant when they occur in utterance-initial position (i.e. cannot start with a vowel) (see Watson 2007:66). Therefore, when Pallaði occurs in utterance-initial position, the definite article is realized as ?al. On the other hand, when ?allaði occurs in non-initial utterance position as in (1) above, the definite article is realized as $l$.

Note 2. The sematic and phonological properties will not be of my primary concern here as the focus will be on the syntax of NRRCs.

Note 3. This example is well-known in the Arabic literature which is referred to as the story of Caliph Abu-bakr with the seller. Caliph Abu-bakr asked a seller: "Would you sell this?". The seller replied: "no ALLAH keep you healthy'. Then, Abu-bakr corrected the seller and asked him to say "no, and may ALLAH keep you healthy".

Note 4. The adjective kabiirat-un is supposed to agree with the modified noun madiinat-un in number, gender, case and definiteness and thus shows related agreement markers. However, in MSA, the case and indefiniteness markers do not appear on the word when it occurs in utterance-final position.

Note 5. Alqurashi (2016) also argues that Pallaði which introduces free relative clause in MSA is a complementizer.

Note 6. The complementizer Pallað $i$ is not used to introduce complement clauses. They are introduced by either ?an (for verb-initial clause) or Panna (for subject-initial clause) as the following illustrate:

(i) a. Piqtarha T-Tabiib-u [?an y?xuða Zayd-un raaћt-a-n li-mudati yawmayn]. suggested.3.M.SG DEF-doctor-NOM that take.3.M.SG Zayd-NOM rest-ACC-IN DEF for-duration two-days 'The doctor suggested that Zayd take rest for the duration of two days.'

$$
\begin{array}{cccc}
\text { b. Paxbartu-k } & \text { [Panna } & \text { Zayd-an } & \text { saafara }] \\
\text { told.1.SG-2.M.SG } & \text { that } & \text { Zayd-ACC } & \text { traveled.3.M.SG }
\end{array}
$$

'I told you that Zayd had travelled.'

It should be noted here that Alotaibi amd Borsley (2013) claim that preverbal subjects in Arabic are in fact topics and thus the clauses following ?anna are really topic-initial and not necessarily subject-initial.

Note 7. De Vries (2006) also assumes that nominal appositions, exemplified in (i), have the same structure as coordination.

(i) John, my boss, is a nice man.

Note 8. Citko (2008) argues against De Vries's analysis, but this is not directly of our concern here as Arabic NRRCs are quite different from their equivalent in English. 